of the articles published in the speciality journals, news related to the research and designing activity, brief plant information, trade notes and statements of visitors of our oil and chemical sector as well as other materials illustrating the steady progress witnessed by the Rumanian oil and chemical industries". It is significantly added that this Centre will supply, on demand, "articles, summaries and other additional information translated into one of the international languages, accompanied by photos". This bulletin is in mimeograph type with no illustrations save coloured advertisements on the inside covers; but the contents - research and design, short news, commercial information, patents-books and reviews, etc., if this pattern is followed in future issues are bound to attract attention and to command a keenly interested following of international oil technologists.
H. B. MILNER

\title{
ATOMIC ENERGY IN AUSTRALIA
}

$\mathrm{T}$ HE twelfth annual report of the Australian Atomic Energy Commission*, for the year ending June 30, 1964 , deals with the production of uranium in Australia, research activities at the Lucas Heights Research Establishment and in Australian universities, and generally with international relationships and nuclear power developments in various countries.

The financial statement records that capital expenditure was reduced by some $£ A 175,000$, but that research expenditure increased by about £A270,000 to nearly £A3 million, largely because of the introduction of improved salary scales for the staff and the increased cost of recruitment of staff. The net operating and capital expenditure for the year was $£ A, 3,473,862$, an increase of $£ A, 287,000$ over the previous year. The advance to the Rum Jungle Project was reduced, however, from $£ A 1.58$ million to $£ A 720,000$.

Uranium continued to be in over-supply throughout the world, but the major cut-backs in production required to stabilize the industry in the Western World are now completed. It is expected that since output will continue to fall as individual mines close down, no additional drastic changes will be necessary, and that in the early 1970's world requirements for nuclear fuel will increase again quite rapidly. During 1963 about 1,200 short tons of uranium oxide were produced and sales during this period were valued at approximately $£ A 5 \cdot 5$ million. Only one sales contract remained in operation in June 1964, and although the United Uranium N.L. expected to complete production during 1964, the final deliveries under the £A5 million contract with the United Kingdom Atomic Energy Authority will extend into 1965. Treatment of stockpiled uranium ore at Rum Jungle is expected to continue at the present level for several years.

The Commission's main research programme is devoted to the investigation of the technical and economic feasibility of a high-temperature, carbon dioxide-cooled, beryllium oxide-moderated, power reactor of the pepple-bed type. The fuel elements consist of a dispersion of thorium oxide and commercial plutonium oxide in beryllia, and the core of the reactor comprises a large number of spheres or pepples, about 1 in. in diameter, of the fuel material. Four different engineering designs of the reactor system are being studied and these are shown diagrammatically in the annual report. Although considerable effort has been devoted to the various engineering and theoretical physics problems involved, including the development of computer codes for core nuclear studies, the Commission specifically states in the report that there is no commit. ment to construct a power reactor in Australia.

At the Lucas Heights Research Establishment the high ngutron flux materials testing reactor, Hifar, continued operation at a power output of 11-MW (thermal) on a 28-day cycle for the whole year, except for a two-month major overhaul period. The small low-power reactor, Moata, was used mainly for experiments associated with the performance of systems moderated with beryllium oxide. Alterations were made in the control rod read-out

* Australia. Twelfth Annual Report of the Australian Atomic Energy Commiseion for the year ended 30th June, 1964 Pp. 80. (Coogee, N.S.W. Australian Atomic Energy Commission, 1964.) system, and to the internal graphite reflector. New facilities completed or installed at the Establishment included a large single cell capable of remote-handling of up to $600,000 \mathrm{c}$. of cobalt- 60 , and a $3 \cdot \mathrm{MeV}$ positive ion Van de Graaff accelerator for fast neutron physics experimonts.

The Establishment maintained a good safety record during the year. No serious accident, either radiological or industrial, occurred. A wide range of radioisotopes was produced for use in medicine, research, agriculture and industry, and in addition to supplying Australian requirements, radioisotopes were exported to Japan, India, New Zealand. South Africa and the Philippines. The development of sources of gamma-excited monoenergetic X-rays and their application in industry were given particular attention. Special projects included the production of sources of caesium-134 and thulium-170 for radiographic purposes, and the investigation of the effects of neutron- and gamma-radiation on non-metallic bonding materials such as epoxy resin. Large sources of high specific activity of cobalt-60 can be produced in Hifar, and during the year the Commission supplied the Royal Adelaide Hospital with a 1,300-c. source, the Royal North Shore Hospital in Sydney with a 2,160-c. source, and under the Colombo Plan, the Cancer Institute of Madras, India, with a 3,025-c. source. The only significant change during the year in the demand for specific radioisotopes was an increased request for radiography sources in smaller sizes and cylindrical sources of iridium-192 of $1-\mathrm{mm}$ length and $1-\mathrm{mm}$ diameter with an activity of up to $8 \mathrm{c}$., and similar sources of cobalt-60 with an activity of $1.5 \mathrm{c}$. were produced to meet this requirement.

The first intermational conference on "Beryllium-oxide", attended by scientists from six countries, was held in Newport, New South Wales, during October 21-25, 1963. The conference was sponsored and organized by the Commission, and 56 papers were presented for discussion, including 27 from the Australian Atomic Energy Commission Research Establishment. The topics discussed covered aspects of fabrication, structure, physical and mechanical properties, radiation damage and gas-solid interactions. The last day of the conference was devoted to a symposium on the utilization of beryllium oxide in reactors. The proceedings of the conference have been published in a special issue of the Journal of Nuclear Materials (1964). In addition to a wide range of booklets, leaflets and other publications on atomic energy, the Commission also published a quarterly journal, Atomic Energy in Australia, a quarterly Radioisotope Newsletter, and a special 55-page booklet entitled $A n$ Introduction to Nuclear Science for use in schools. The Commission's film "Atoms for Everyday" was shown on the national television network and a major exhibition, "Australia and the Atom", featuring many aspects of atomic research, production and mining of uranium, nuclear power and the use of radioisotopes, was presented in Brisbane and Newcastle. The Research Establishment held open days during September 26-28, 1963, and some 6,000 persons visited and inspected it.

Research contracts totalling more than 1 A51,000 were placed with Australian universities. Details of these are 
listed in an appendix to the report. The Commission, together with the ten Australian universities, constitutes the corporate membership of the Australian Institute of Nuclear Science and Engineering, which is governed by the Institute Council consisting of one representative from each of the universities and four from the Commission. All member universities are engaged in training nuclear scientists and engineers and in related research. 112 projects were supported by research and training grants of the Institute, and the expenditure amounted to about $£ A 100,000$. Plasma physics, in particular, received special support. An informal conference on plasma physics was held during November 1963, and the research effort at three universities was assisted by providing on loan a special high-speed camera capable of photographing the formation and decay of plasmas. Two other informal specialists conferences were held at Lucas Heights under the auspices of the Institute-a "Heat Transfer and Fluid Flow" conference during August 1963, and a "Radiation Chemistry" conference during October 1963.

In conjunction with the University of New South Wales, the Commission is to establish an Australian School of Nuclear Technology with headquarters at the Lucas Heights Research Establishment. The facilities of both the Research Establishment and the University will be available to the School. The aim is to promote formal training and education in nuclear technology; and fulltime courses of varying length in the science and technology of nuclear reactors, the production and application of radiosotopes, radiological safety and health physics, etc., will be open to students from Australia and overseas.

S. Weintroub

\section{BRITISH CHEMICAL REFERENCE SUBSTANCES}

$\mathrm{I}_{\mathrm{P}}^{\mathrm{N}}$ late 1963, the General Medical Council and the Pharmaceutical Society of Great Britain agreed to set up a joint authority to prepare and distribute chemical reference substances needed to carry out certain tests and assays described in the British Pharmacopoeia, the British Pharmaceutical Codex and the British Veterinary Codex. The Joint Committee held its first meeting in March 1964, and established a number of panels. Each panel was charged with the task of establishing one or more of these reference substances, and, since these substances might be of value for other purposes, the panels were asked, should it prove impracticable to obtain absolute purity, to ascertain so far as possible the amounts of all impurities.

The first two "British Chemical Reference Substances" have now been made available: digoxin and 2-t-butyl-4methoxyphenol (the most active isomer present in butylated hydroxyanisole); these are required for the Addendum 1964 to the British Pharmacopoeia 1963, which became official as from June 1, 1965. The reports to the Joint Committee of the panel responsible on the preparation and purity of these substances have now been published.

The digoxin reference substance is required in the assay of digoxin and of its two preparations, the injection and the tablets, and for purposes of comparison (in place of the previously used authentic specimen) in the infra-red identification test. From its examination of the reference substance, the panel concluded that the substance is at least 99.7 per cont pure, containing not more than a total of $0 \cdot 3$ per cent of gitoxin, acetyldigoxin, digoxigenin and digitoxin.

The 2-t-butyl-4-methoxyphenol reference substance is required for the assay of butylated hydroxyanisole and in the infra-red identification test. In this case, a purity of at least 99.85 per cent has been achieved, the balance being made up of very small amounts of $3,3^{\prime}$-di-( $t$-butyl)$2,2^{\prime}$-dihydroxy-5,5'-dimethoxybiphenyl (bis-BHA), 2,5di-(t-butyl)-4-methoxyphenol, 4-methoxyphenol and a trace of an unidentified impurity. As well as its pharmaceutical uses, butylated hydroxyanisole has extensive usage in the food industry as an anti-oxidant in oils and fats, and the establishment of this reference substance will be welcomed in fields outside of pharmacy.

Samples of these reference substances are distributed by the Pharmaceutical Society and are available on application to the Assistant Director, Department of Pharmaceutical Sciences, 17 Bloomsbury Square, London, W.C.1, at a cost of $£ 410 \mathrm{~s}$. for $0.3 \mathrm{~g}$ of the digoxin, and $£ 3$ for $0.2 \mathrm{~g}$ of the 2-t-butyl-4-methoxyphenol. Copies of the panel's reports can be obtained from either of the joint secretaries, Mr. T. C. Denston, 44 Hallam Street, London, W.1, and Dr. K. R. Capper, 17 Bloomsbury Square, London, W.C.1.

Because there may be some confusion between "British Chemical Reference Substances" and "Authentic Specimens", both of which are distributed by the Pharmaceutical Society, it is appropriate to explain that the reference substances are samples which have been purified so far as is practically and economically feasible, any remaining impurities having been identified and a limit set on their presence. They are used in assay procedures and to serve as the reference material in tests used to limit the presence of certain impurities in pharmacopoeial and Codex substances. Authentic specimens, on the other hand, are only tested samples of good quality commercial material which are needed for certain tests, notably infra-red identification tests, for which a comparison material having the purity of a reference substance is not essential.

\section{PESTICIDES IN THE ENVIRONMENT}

\begin{abstract}
$\Delta \mathrm{N}$ advanced study institute on "Pesticides in the Environment and their Effects on Wildlife", sponsored by the North Atlantic Treaty Organization, was held at Monks Wood Experimentsl Station during July 1-14.

The main purpose of the Institute was to enable those working on the effects of pesticides on wildlife to exchange ideas and to discuss future research. Thirty-four papers were read, and dealt with the background of the wildlife problem and with field and laboratory studies of the effects of pesticides in terrestrial, freshwater and marine environments. Seventy-one scientists from Government
\end{abstract}

and university laboratories attended the moeting, including chemists, toxicologists and zoologists of eleven nationalities.

The papers and discussions showed that pesticide residues have been detected in a wide spectrum of physical and biological samples from diverse environments, indicating that contamination is widespread. In some instances, harmful effects on wildlife populations were clearly demonstrated, but more frequently the effects of residues are unknown.

It was concluded that in order to understand the effects of pesticides more fully, there was need for more work, 